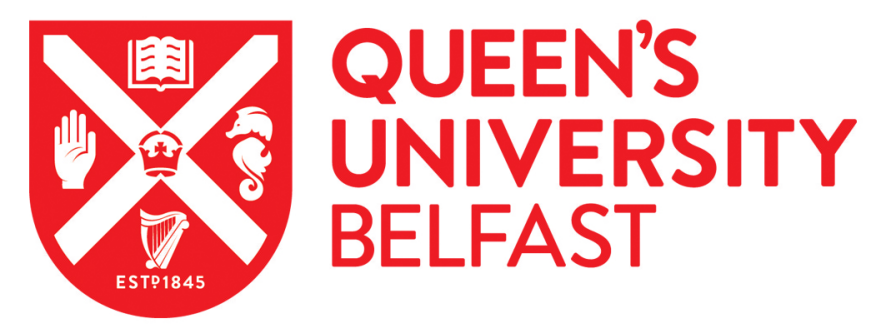

\title{
Increasing recoverable energy storage in electroceramic capacitors using "dead-layer" engineering
}

McMillen, M., Douglas, A. M., Correia, T. M., Weaver, P. M., Cain, M. G., \& Gregg, J. M. (2012). Increasing recoverable energy storage in electroceramic capacitors using "dead-layer" engineering. Applied Physics Letters, 101(24), [242909]. https://doi.org/10.1063/1.4772016

Published in:

Applied Physics Letters

Document Version:

Publisher's PDF, also known as Version of record

Queen's University Belfast - Research Portal:

Link to publication record in Queen's University Belfast Research Portal

Publisher rights

Copyright 2012 American Institute of Physics. This article may be downloaded for personal use only. Any other use requires prior permission of the author and the American Institute of Physics.

\section{General rights}

Copyright for the publications made accessible via the Queen's University Belfast Research Portal is retained by the author(s) and / or other copyright owners and it is a condition of accessing these publications that users recognise and abide by the legal requirements associated with these rights.

Take down policy

The Research Portal is Queen's institutional repository that provides access to Queen's research output. Every effort has been made to ensure that content in the Research Portal does not infringe any person's rights, or applicable UK laws. If you discover content in the Research Portal that you believe breaches copyright or violates any law, please contact openaccess@qub.ac.uk. 


\section{AIP Appiled Physics \\ Letters}

\section{Increasing recoverable energy storage in electroceramic capacitors using "dead-layer" engineering}

M. McMillen, A. M. Douglas, T. M. Correia, P. M. Weaver, M. G. Cain et al.

Citation: Appl. Phys. Lett. 101, 242909 (2012); doi: 10.1063/1.4772016

View online: http://dx.doi.org/10.1063/1.4772016

View Table of Contents: http://apl.aip.org/resource/1/APPLAB/v101/i24

Published by the American Institute of Physics.

\section{Related Articles}

Strain controlled ferroelectric switching time of $\mathrm{BiFeO} 3$ capacitors

Appl. Phys. Lett. 101, 242908 (2012)

Temperature-dependent capacitance-voltage analysis of defects in Al2O3 gate dielectric stacks on GaN Appl. Phys. Lett. 101, 241606 (2012)

Space-charge-limited currents in polyimide films

Appl. Phys. Lett. 101, 242905 (2012)

Sensitivity analysis of scanning microwave microscopy for nano-scale dopant measurements in $\mathrm{Si}$ J. Appl. Phys. 112, 104325 (2012)

Ultrahigh arsenic sorption using iron oxide-graphene nanocomposite supercapacitor assembly J. Appl. Phys. 112, 104315 (2012)

\section{Additional information on Appl. Phys. Lett.}

Journal Homepage: http://apl.aip.org/

Journal Information: http://apl.aip.org/about/about_the_journal

Top downloads: http://apl.aip.org/features/most_downloaded

Information for Authors: http://apl.aip.org/authors

\section{ADVERTISEMENT}

\section{AIP Applied Physics Letters}

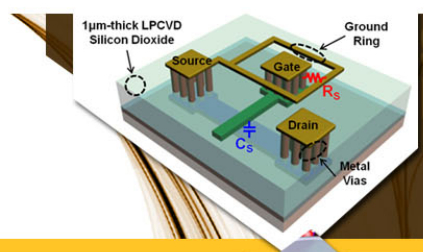

\section{SURFACES AND} INTERFACES

Focusing on physical, chemical, biological structural, optical, magnetic and electrical properties of surfaces and interfaces, and more..

\section{EXPLORE WHAT'S NEW IN APL}

SUBMIT YOUR PAPER NOW!
ENERCY CONVERSION AND STORACE 


\title{
Increasing recoverable energy storage in electroceramic capacitors using "dead-layer" engineering
}

\author{
M. McMillen, ${ }^{1}$ A. M. Douglas, ${ }^{1}$ T. M. Correia, ${ }^{2}$ P. M. Weaver, ${ }^{2}$ M. G. Cain, ${ }^{2}$ \\ and J. M. Gregg ${ }^{1, a)}$ \\ ${ }^{1}$ Centre for Nanostructured Media, School of Maths and Physics, Queen's University Belfast, Belfast, \\ BT7 INN, Northern Ireland, United Kingdom \\ ${ }^{2}$ National Physical Laboratory, Hampton Road, Teddington, Middlesex TW11 OLW, United Kingdom
}

(Received 3 October 2012; accepted 28 November 2012; published online 12 December 2012)

\begin{abstract}
The manner in which ultrathin films of alumina, deposited at the dielectric-electrode interface, affect the recoverable energy density associated with $\left(\mathrm{BiFeO}_{3}\right)_{0.6}-\left(\mathrm{SrTiO}_{3}\right)_{0.4}$ (BFST) thin film capacitors has been characterised. Approximately $6 \mathrm{~nm}$ of alumina on $400 \mathrm{~nm}$ of BFST increases the maximum recoverable energy of the system by around $30 \%$ from $\sim 13 \mathrm{Jcc}^{-1}$ to $\sim 17 \mathrm{Jcc}^{-1}$. Essentially, the alumina acts in the same way as a naturally present parasitic "dead-layer," distorting the polarisation-field response such that the ultimate polarisation associated with the BFST is pushed to higher values of electric field. The work acts as a proof-of-principle to illustrate how the design of artificial interfacial dielectric "dead-layers" can increase energy densities in simple dielectric capacitors, allowing them to compete more generally with other energy storage technologies. (C) 2012 American Institute of Physics. [http://dx.doi.org/10.1063/1.4772016]
\end{abstract}

Whilst not a mainstay solution for general energy storage problems, simple capacitors based on electroceramic dielectric layers are currently being taken seriously for specific niche aspects of clean energy technology. Charge and discharge rates are extremely fast compared to Li-ion batteries or fuel cells and they are hence an obvious choice for pulsepower applications. ${ }^{1-3}$ Equally, as their operation is not reliant on the kinetics associated with large-scale ion migration, they can demonstrate strong thermal stability, ${ }^{4}$ and can operate reliably in high temperature environments where other technologies struggle. ${ }^{5,6}$ A major drawback, however, is that the energy stored per unit volume (energy density) in bulk and thick film devices is relatively low: in $\mathrm{BaTiO}_{3}, \mathrm{SrTiO}_{3}$ (STO), or $\mathrm{PbZrO}_{3}$ bulk ceramics ${ }^{7}$ and in commercial $\mathrm{X} 7 \mathrm{R}$ capacitors $^{8,9}$ typical energy densities have been found to be $1-2 \mathrm{Jcc}^{-1}$. Slightly higher values $\left(\sim 6 \mathrm{Jcc}^{-1}\right)$ have been demonstrated in other material systems, ${ }^{8,9}$ but are still relatively modest.

The energy density that is recoverable after charging an electroceramic material in a capacitor structure to the point where it develops a polarisation $P^{\prime}$ is given by

$$
\int_{P_{r}}^{P^{\prime}} E(P) d P(\text { upon discharging), }
$$

where $E$ is the electric field, $P$ is the polarisation, and $P_{r}$ is the remanent polarisation. The value of this integral obviously depends on the form of the polarisation-field discharge function and in theory that could range anywhere from zero (for a ferroelectric with a perfectly square hysteresis loop $\left(P_{r}=P^{\prime}\right.$ ) to $E\left(P^{\prime}\right) P^{\prime}$ (for a perfectly selected antiferroelectric). Of course, in reality, square-loop ferroelectrics are not relevant for this kind of energy storage application. Instead, low remanent polarisation is a key feature in materials selection. Once this property criterion is satisfied, however, the

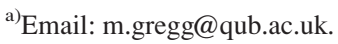

recoverable energy density is actually only moderately sensitive to the form of the $P-E$ discharge function, with typically much less than an order of magnitude difference between a strongly non-linear slim-looped dielectric and the perfect antiferroelectric.

Consequently, the overriding factor in determining major changes in recoverable energy density is the value of $E\left(P^{\prime}\right) P^{\prime}$ that can be achieved before breakdown. Large electroceramic polarisations are of the order of $\sim 100 \mu \mathrm{Ccm}^{-2}$ (Refs. 10-12) and while this value could increase slightly, it is physically limited by both the ionic charges of the species in the material and the physical dimensions of the crystallographic unit cell. Thus, it is primarily the electric field, at which the ultimately saturated polarisation in the electroceramic is achieved, which offers the greatest scope for manipulation in order to dramatically enhance energy storage properties.

The effect of manipulating the field at which saturated polarisation occurs can be seen explicitly by considering the fictitious example illustrated in Figure 1(a). Here two slimloop polarisation-field curves are presented (A and B) along with the energy stored in each as a function of field (calculated according to Eq. (1)). Both "A" and "B" have the same ultimate value of saturated polarisation. However, the energy storage characteristics are quite different: at low values of applied field, "A" stores more energy than "B," but after the polarisation in "A" has saturated, the energy that can be stored in "B" continues to increase until it far surpasses that developed in "A." The "smearing" of the polarisation development to higher field values is therefore distinctly beneficial in increasing ultimate energy storage capacity.

Hints as to how polarisation smearing to high field values might be successfully realised in real systems are already manifest in the functional characteristics of most thin film capacitors: Figure 1(b) presents the typical variation in $P-E$ behaviour that is seen between bulk ceramic or single crystal material and carefully grown thin films (in this case for $\mathrm{BiFeO}_{3}$ (Refs. 10-12)). While the limiting polarisation 


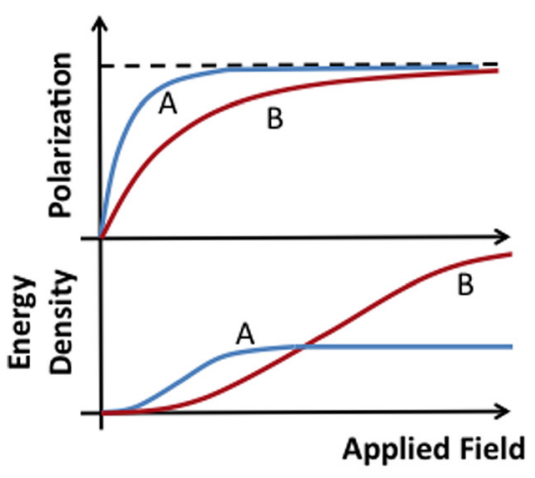

(a)

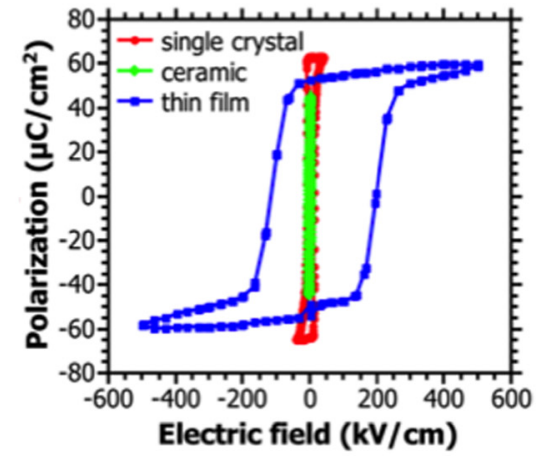

(b)
FIG. 1. (a) Fictitious capacitor systems "A" and "B" both develop the same ultimate saturated polarisation (top), but at different field values. While "A" develops greater energy storage capabilities at low fields (bottom), the ultimate energy storage capabilities of "B" are superior. Polarization-electric field $(P-E)$ loops from single crystal, ceramic and thin film $\mathrm{BiFeO}_{3}$ (b). Whilst the ultimate achievable polarization is similar for all three systems, an order of magnitude increase in the field at which the saturated polarisation develops is evident for the thin film. This is one manifestation of the so-called "dead-layer," Data have been extracted from Refs. 10-12. developed is similar in all cases $\left(\sim 60 \mu \mathrm{Ccm}^{-2}\right)$, and is a fundamental property of the electroceramic, the field required to achieve saturation is significantly larger for the $200 \mathrm{~nm}$ thin film than for the bulk.

This observation can be alternatively expressed as a dramatic reduction in the effective permittivity $(\Delta P / \Delta E)$ in the thin film structure. Reduced permittivity in thin films is an almost ubiquitous observation, commonly understood to be due to the presence of a parasitic low permittivity "deadlayer" (or interfacial capacitance), at the electroceramicelectrode interface, which acts electrically in series with the "bulk-like" high permittivity film. While strongly influential interfacial capacitance layers pose a significant problem for applications that rely on high permittivity, for energy storage devices they could clearly be advantageous. This is reflected in the energy density values already found in thin film electroceramic capacitors. These are typically $\sim 15 \mathrm{Jcc}^{-1}$ or greater, ${ }^{13-16}$ with energy densities as high as $53 \mathrm{Jcc}^{-1}$ reported $^{17}$ (compare with bulk values given above).

In this letter, we have explored the possibility of augmenting and enhancing recoverable energy densities by deliberately engineering strong interfacial capacitance effects. The $P-E$ response of thin film capacitors containing the slim-looped dielectric of nominal composition $\left(\mathrm{BiFeO}_{3}\right)_{0.6}-\left(\mathrm{SrTiO}_{3}\right)_{0.4}$ (BFST) have been monitored before and after the deposition of an ultrathin film of alumina at the electrode-electroceramic boundary. Results clearly show that the polarisation that can be induced remains unaffected by the introduction of the alumina layer, but, as expected, the effective field at which this polarisation is generated is significantly increased. As a consequence, the recoverable energy density also increases. Such observations clearly indicate that interface design at the electrode-electroceramic boundary could be a critical tool for optimising the energy densities found in simple dielectric capacitors; indeed, it offers a strategy that may allow them to compete more generally with other energy storage technologies.

A ceramic target, for use in pulsed laser deposition (PLD), was prepared by conventional solid-state reaction techniques: $\mathrm{Bi}_{2} \mathrm{O}_{3}, \mathrm{Fe}_{2} \mathrm{O}_{3}$, and $\mathrm{SrTiO}_{3}$ powders were mixed and "calcined" to produce a single phase perovskite of nominal composition $\left(\mathrm{BiFeO}_{3}\right)_{0.6}-\left(\mathrm{SrTiO}_{3}\right)_{0.4}$, along with some excess bismuth oxide (associated with a deliberate $10 \% \mathrm{~mol}$ $\mathrm{Bi}$ excess in the powder to help accommodate for losses due to species volatility). After milling, the calcined powder was pressed (uniaxially) and sintered at $1100{ }^{\circ} \mathrm{C}$ for $30 \mathrm{~min}$ in a conventional air-furnace. Films were fabricated by PLD on $\{100\}$ STO substrates, using a $\mathrm{KrF}$ excimer laser $(\lambda=248 \mathrm{~nm})$ operated at a pulse frequency of $10 \mathrm{~Hz}$. A substrate temperature of $650{ }^{\circ} \mathrm{C}$ was used for all depositions. A $50 \mathrm{~nm}$ bottom electrode of $\mathrm{SrRuO}_{3}$ (SRO) was first deposited in 0.133 mbar $\mathrm{O}_{2}$. The oxygen pressure was then adjusted to 0.027 mbar and this was maintained during the deposition of the BFST film $(400 \mathrm{~nm})$. After deposition, samples were allowed to cool at a rate of $10{ }^{\circ} \mathrm{C} \mathrm{min}^{-1}$ in $800 \mathrm{mbar}_{2}$ to an annealing temperature of $450{ }^{\circ} \mathrm{C}$ and were held at this temperature for $30 \mathrm{~min}$. After subsequent cooling to room temperature, a hard-mask was used to define sputtered $\mathrm{Au}$ electrodes, $0.5 \mathrm{~mm}$ in diameter. After electrical characterisation, samples were then sputter-coated with an ultrathin film of aluminium at room temperature which was subsequently oxidised to alumina by heating in air for $30 \mathrm{~min}$ at $100^{\circ} \mathrm{C}$. New gold electrodes were then deposited (between the electrodes that had previously been deposited) to allow further electrical characterisation of the BFST with the alumina layer now present at the electrode-electroceramic interface. Room temperature $P-E$ hysteresis measurements were performed at $1 \mathrm{kHz}$ on a Radiant Precision materials analyzer (the recorded loops resulted after an initial poling cycle had been performed).

Information from typical $\theta-2 \theta$ XRD scans of the BFST thin film capacitor structures is shown in Figure 2. The films appear to be highly $\{100\}_{\text {pseudocubic }}$ oriented, with no evidence of secondary phases observed. Transmission electron microscopy (TEM) and energy dispersive x-ray analysis (EDX) suggested a cation composition that was somewhat bismuth deficient and strontium rich $(13 \% \mathrm{Bi}, 18 \% \mathrm{Fe}, 38 \% \mathrm{Sr}$, and $31 \% \mathrm{Ti})$ compared to the targeted $\left(\mathrm{BiFeO}_{3}\right)_{0.6}-\left(\mathrm{SrTiO}_{3}\right)_{0.4}$.

Figure 3 presents an EDX line profile (taken on TEM) of relative cation concentrations (represented by integrated counts) as a function of position taken on a cross-section of a capacitor structure with the ultrathin alumina layer already deposited. The alumina layer is approximately $6 \mathrm{~nm}$ thick as judged from the full-width half-maximum of the peak in the aluminium EDX counts with position. The apparent background aluminium signal in the BFST film results from characteristic X-rays associated with electron relaxation in titanium contributing to counts within the energy window assigned to be characteristic of aluminium. 


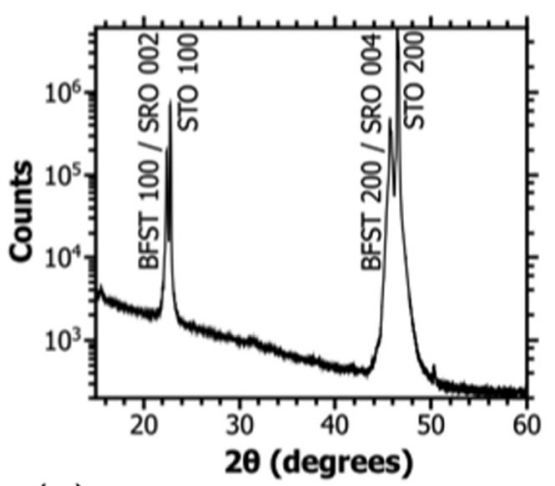

(a)

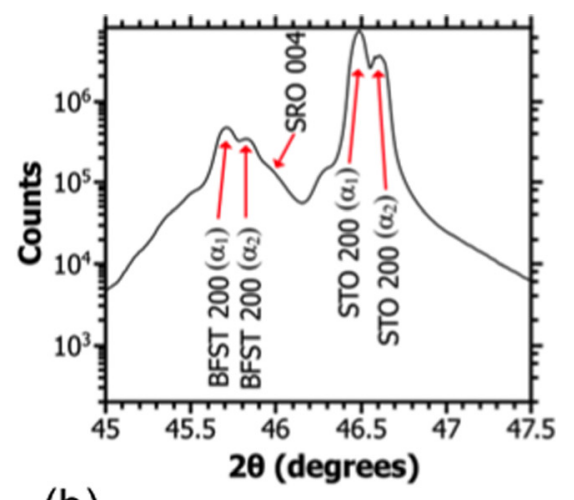

(b)
FIG. 2. X-ray diffraction (coupled $\theta-2 \theta$ scan) of a typical bismuth ferrite-strontium titanate (BFST) based thin film capacitor sample. Films appear to be single phase and strongly oriented.
$P-E$ characteristics obtained from two identically processed thin film capacitor samples (denoted as A and B) before and after the introduction of the ultrathin alumina layer are shown in Figure 4. BFST clearly behaves as a slim-looped non-linear dielectric, which can develop quite considerable polarisation (of the order of $50 \mu \mathrm{Ccm}^{-2}$ ) and in itself looks like a good candidate for energy storage applications. Indeed, even without the alumina interfacial layer, the thin film capacitors demonstrated energy densities of approximately $13 \mathrm{Jcc}^{-1}$ (Figures 4(c) and 4(d)); recoverable energy density was calculated according to Eq. (1) using trapezium-rule numerical integration). The addition of the alumina noticeably increased the measured coercive field, but also pushed the ultimate polarisation that could be achieved in the BFST to larger effective electric field values, as would be expected given the discussions above. The increased coercive field was also associated with an increased value of remanent polarisation. Despite this, the energy density as a function of polarisation was generally larger with the alumina interfacial film present than without it and maximum values of $\sim 17 \mathrm{Jcc}^{-1}$ were observed (Figures 4(c) and 4(d)). This represents a $\sim 30 \%$ increase in recoverable energy density over the simple BFST thin film capacitor structure.

As discussed above, the capacitor structure described here behaves as a low permittivity "dead layer" in series with a thicker layer of higher permittivity. Because the electric displacement in the ferroelectric layer is unchanged between the "before" and "after" experiments, the electric field in this layer is also unchanged. The increased average electric field is due to a voltage drop across the low permittivity layer. Assuming the low permittivity layer behaves as a linear dielectric, this equates to $35 \%$ of the total voltage across the structure, implying an electric field of $24 \mathrm{MV} \mathrm{cm}^{-1}$ across this layer. This also means that approximately $35 \%$ of the recoverable energy is associated with the electric field in the low permittivity layer, comparable with the observed increase in energy density. As noted above, the determining factor in the energy density is the size of the electric field that can be obtained without breakdown. Ideally the energy would be stored in a very high electric field applied across a very thin film. A significant problem with this approach is that although the energy density is very high, the total volume of material and, therefore, the total energy is very small unless the film can be produced in very large areas. For example, to store $1 \mathrm{~kJ}$ using a $6 \mathrm{~nm}$ thick film at $10 \mathrm{~J} \mathrm{~cm}^{-1}$ would require an area of nearly $20000 \mathrm{~m}^{2}$. Even if the technology were available to produce this large area of film, the probability of doing so with no short-circuit defects would be vanishingly small. The structure described here overcomes this obstacle because any breakdown in the highly stressed low permittivity layer would not result in a current path. Rather than a short-circuit failure of the whole device, the result would be just a minor loss in energy storage in the region of the defect. In this case the ferroelectric layer behaves, not as the energy storage medium, but as a short-circuit to electric flux, and open circuit to electric current. If this idealisation were reached, then the ferroelectric layer would be just providing back-up insulation without contributing to the stored energy, i.e., the ferroelectric layer would be the "dead layer." In practice, the optimum energy density would be obtained by engineering the ferroelectric and low permittivity layers so that they are both subjected to sustainable levels of electric stress. Both layers would then contribute to the overall stored energy whilst providing insulation back-up to each other.

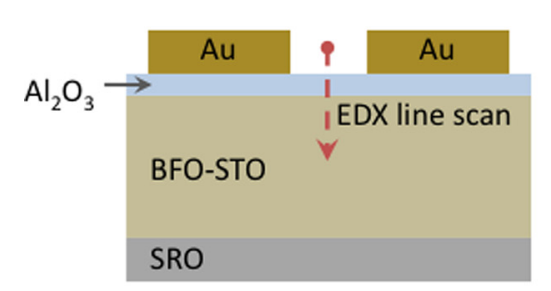

(a)

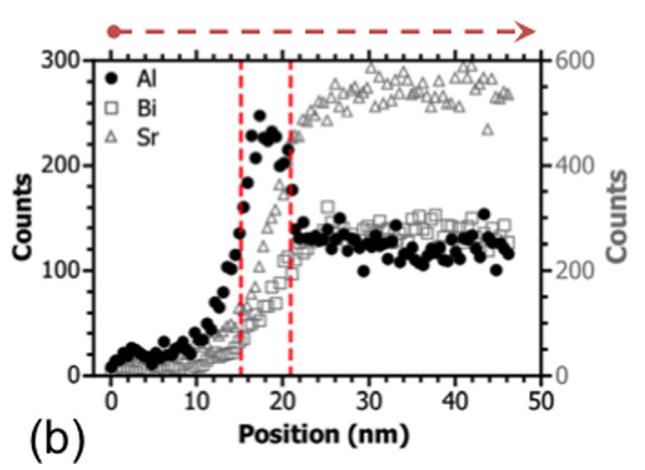

FIG. 3. A schematic of the thin film capacitor structure with an ultrathin alumina layer introduced at the electrode-electroceramic interface (a). A nanoprobe energy dispersive X-ray analysis (taken on a transmission electron microscope) along the line indicated by the red-dashed arrow in (a) suggests that the thickness of the alumina layer is of the order of $\sim 6 \mathrm{~nm}$ (b). 
(a)

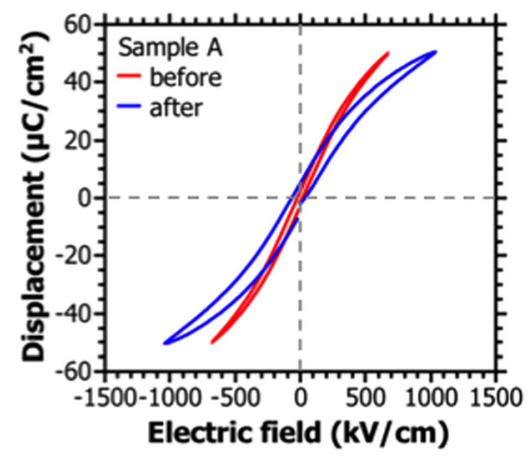

(b)

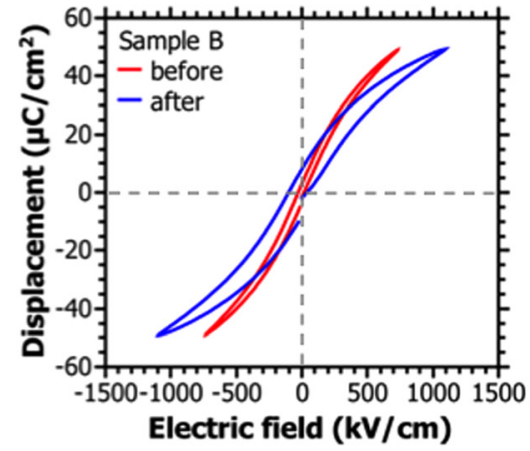

(c)

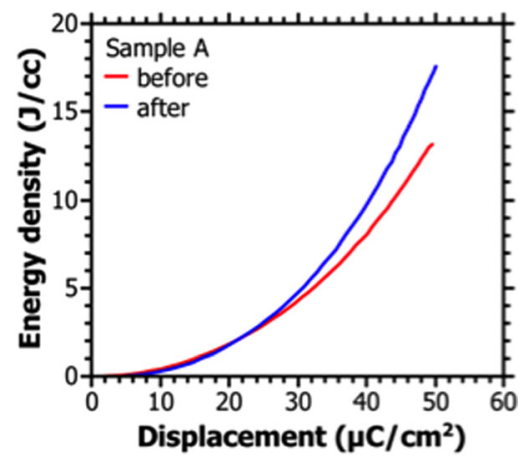

(d)

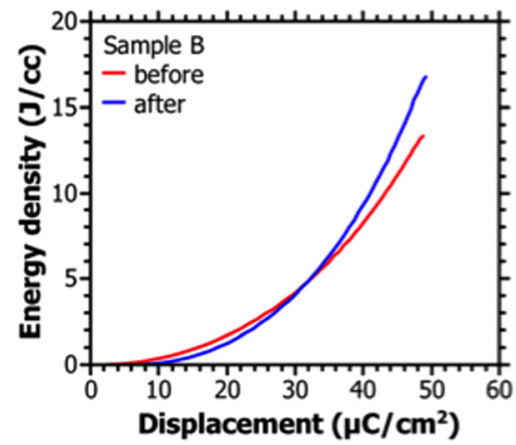

FIG. 4. $D-E$ hysteresis loops from two thin film capacitor structures (a, b) before (red) and after (blue) the introduction of an alumina layer at the electrode-BFST interface. The associated recoverable energy density plotted as a function of polarization (c, d) was obtained by numerical integration and shows the increase in energy density induced by the introduction of an engineered "dead-layer."
In conclusion, the enhancement of the recoverable energy density in thin film capacitors of BFST by the deliberate addition of an interfacial "dead-layer" has been observed. Characterisation of the $P-E$ response of the capacitors before and after deposition of an alumina layer approximately $6 \mathrm{~nm}$ thick at the dielectric-electrode interface indicated an increase of $\sim 30 \%$ in recoverable energy density, from $\sim 13 \mathrm{Jcc}^{-1}$ to $\sim 17 \mathrm{Jcc}^{-1}$. The distortion of polarisation-field response means that the ultimate polarisation is achieved at higher electric field values. Although this configuration imposes a high electric field across the "dead layer," it is protected from breakdown failure by the ferroelectric layer which experiences a much lower electric field. The design of the electrode-dielectric interface in simple capacitors could provide a strategy for optimisation of energy densities of such devices and a method for improving immunity to breakdown failure in a large area device.

The authors acknowledge the financial support of the Technology Strategy Board and the UK National Measurement Office.

${ }^{1}$ S. Kwon, W. Hackenberger, E. Alberta, E. Furman, and M. Lanagan, IEEE Electr. Insul. Mag. (USA) 27, 43 (2011).

${ }^{2}$ A. S. Aricò, P. Bruce, B. Scrosati, J.-M. Tarascon, and W. van Schalkwijk, Nature Mater. 4, 366 (2005).
${ }^{3}$ M. T. Domonkos, S. Heidger, D. Brown, J. V. Parker, C. W. Gregg, K. Slenes, W. Hackenberger, S. Kwon, E. Loree, and T. Tran, IEEE Trans. Plasma Sci. 38, 2686 (2010).

${ }^{4}$ J. B. Lim, S. Zhang, N. Kim, and T. R. Shrout, J. Am. Ceram. Soc. 92, 679 (2009).

${ }^{5}$ M.-J. Pan and C. A. Randall, IEEE Electr. Insul. Mag. (USA) 26, 44 (2010).

${ }^{6}$ R. W. Johnson, J. L. Evans, P. Jacobsen, J. R. Thompson, and M. Christopher, IEEE Trans. Electron. Packag. Manuf. 27, 164 (2004).

${ }^{7}$ I. Burn and D. M. Smyth, J. Mater. Sci. 7, 339 (1972).

${ }^{8}$ G. R. Love, J. Am. Ceram. Soc. 73, 323 (1990).

${ }^{9}$ H. Ogihara, C. A. Randall, and S. Trolier-McKinstry, J. Am. Ceram. Soc. 92, 1719 (2009).

${ }^{10}$ J. Wang, J. B. Neaton, H. Zheng, V. Nagarjan, S. B. Ogale, B. Liu, D. Viehland, V. Vaithyanathan, D. G. Schlom, U. V. Waghmare, N. A. Spaldin, K. M. Rabe, M. Wuttig, and R. Ramesh, Science 299, 1719 (2003).

${ }^{11}$ D. Lebeugle, D. Colson, A. Forget, and M. Viret, Appl. Phys. Lett. 91, 022907 (2007).

${ }^{12}$ V. V. Shvartsman, W. Kleemann, R. Haumont, and J. Kreisel, Appl. Phys. Lett. 90, 172115 (2007).

${ }^{13}$ J. Parui and S. B. Krupanidhi, Appl. Phys. Lett. 92, 192901 (2008).

${ }^{14}$ K. Yao, S. Chen, M. Rahimabady, M. S. Mirshekarloo, S. Yu, F. E. H. Tay, T. Sritharan, and L. Lu, IEEE Trans. Ultrason. Ferroelectr. Freq. Control 58, 1968 (2011).

${ }^{15}$ B. A. Tuttle, G. Brennecka, D. P. Williams, M. A. Rodriguez, T. J. Headley, and J. S. Wheeler, High Energy Density PLZT Thin Film Capacitors, in Advanced Dielectric, Piezoelectric and Ferroelectric Thin Films, edited by B. A. Tuttle, C. Chen, Q. Jia, R. Ramesh (John Wiley \& Sons, Inc., Hoboken, NJ, USA, 2006), Vol. 162.

${ }^{16}$ D. Kan, C.-J. Cheng, V. Nagarajan, and I. Takeuchi, J. Appl. Phys. 110, 014106 (2011).

${ }^{17}$ B. Ma, D.-K. Kwon, M. Narayanan, and U. Balachandran, J. Mater. Res. 24, 2993 (2009). 